\title{
An Improved MRAS Based Sensorless Vector Control Method for Wind Power Generator
}

\author{
B. Dumnic ${ }^{* 1}$, V. Katic ${ }^{2}$, V. Vasic ${ }^{3}$, D. Milicevic ${ }^{4}$, M. Delimar ${ }^{5}$ \\ 1,2,3,4 Faculty of Technical Sciences, Department of Power and Electronic Engineering \\ University of Novi Sad \\ Novi Sad, Serbia \\ *dumnic@uns.ac.rs \\ ${ }^{5}$ Faculty of Electrical Engineering and Computing, Department of Power Systems \\ University of Zagreb \\ Zagreb, Croatia
}

\begin{abstract}
This paper describes an improved sensorless vector control strategy for a squirrel cage induction generator used in variable speed wind energy conversion systems (WECS). The main goal is to design a robust control algorithm immune to generator parameter variations. In order to estimate the rotational speed of the induction generator, a model reference adaptive system (MRAS observer) is used. It is shown that a generator parameter mismatch has a great influence on the rotor speed estimation. In order to estimate the speed accurately, the generator stator resistance must be identified at the same time to correct the mismatched resistance value used in the observer. The proposed rotor speed estimator with parallel stator resistance identification is first verified by computer simulation. Finally, the experiment is conducted in order to verify the obtained simulation results. It is proved that this control scheme can enhance the efficiency of a variable speed WECS.
\end{abstract}

Keywords: generators, machine vector control, parameter estimation, sensorless control, wind power generation.

\section{Introduction}

In the last fifteen years, wind turbine power generation has noticeably increased worldwide. One of the simplest methods of running a WECS is to use an induction generator connected directly to the power grid [1, 2]. This method of operation forces the machine to run at a constant frequency and therefore at nearly constant speed. Wind power pulsation is thus transferred almost directly to the electrical grid. Furthermore, there is no control of active and reactive powers, which are typically important control parameters to regulate the frequency and the voltage.

Due to the variability of wind speed, it is highly desirable to operate a wind turbine at variable speeds. Besides this, as the power range of the wind turbine increases, those control parameters become more important, and it is necessary to introduce power electronics [3] as an interface between the wind turbine and the grid. A variable speed wind turbine improves the dynamic behavior of the turbine and allows operation at the maximum power-producing point for a given wind speed and control of active and reactive power flow. Other advantages are reduced mechanical stresses, reduced torque and power pulsations, improved power quality and reduced noise at low wind speeds $[4,5]$. These characteristics are changing the nature of the wind turbine from energy source to active power source.

Induction generators are widely used for wind energy conversion systems [6]. The advantages of cage induction generators are well known. Such machines are relatively inexpensive, robust and low maintenance. When induction machines operate using vector control techniques, fast dynamic response and accurate torque control are obtained. For vector control purposes it is necessary to have a signal of induction generator rotor speed. Usually, an encoder or a tachogenerator is used to measure the generator speed. These speed sensors are sensitive to heat and vibrations, require additional wiring work, maintenance, and thus reduce the robustness of the overall system. Therefore, by eliminating the 
speed sensor, the reliability of the WECS is improved and the cost is reduced.

The sensorless drive control has been widely studied in recent years because of numerous advantages over the drives with shaft sensors. Such sensorless systems have been developed for induction motor drives and are well-known among researchers and industry [7]. However, a vast majority of speed estimation schemes require accurate knowledge of almost all machine parameters such as stator and rotor resistance [810]. The accurate value of stator resistance in general motor drives is of the utmost importance for the correct operation of sensorless drives, especially at full load and low speeds. Nevertheless, the most common induction generators operate at relative high speeds (e.g., standard 4-pole induction generator, rated speed $1500 \mathrm{rpm}$, has speed range of 600-1600 rpm) [11], hence the effect of incorrect operation of the speed estimation scheme at low speeds is not expressed. WECS with a fully loaded induction generator is the most critical situation in practice for correct sensorless operation in terms of parameter mismatch. Therefore, if the stator resistance is not accurately known, it could greatly influence speed estimation as well as rotor flux orientation. The steady-state speed error can lead to reduced efficiency of the WECS, taking into account that the speed information is necessary in order to apply the optimum power tracking algorithm [12, 13]. Besides this, the accurate value of rotor resistance is also important for the correct operation of the indirect vector controller [7].

This paper deals with a full-controlled WECS equipped with an induction generator. The induction generator is connected to the utility grid using a back-to-back converter. It consists of two identical PWM converters connected via DC link. One converter is on the generator side providing $A C / D C$ conversion, while the other is on the grid side providing DC/AC conversion. Such configuration enables decoupled control of both converters and their independent analysis. The significance of this paper lies in the control of a generator-side converter. The discussion deals with a sensorless control structure based on an indirect, rotor flux oriented, vector-control system for variable-speed wind energy applications. A detailed analysis is presented of parameter mismatch influence on the stability of the system as well as losses in generated power. An improved method is proposed for online identification of the stator resistance. The stator resistance estimation is developed in conjunction with the rotor flux based speed estimator operating in the stationary reference frame [14, 15]. The calculation of the error signal is based on differences in rotor flux component values obtained as the output of reference and adjustable models. The speed signal, obtained from a model reference adaptive system - MRAS, is used to control the electrical torque of the induction generator. The proposed robust control structure is verified by computer simulation and experiments.

\section{Variable-speed wind energy conversion system}

\subsection{Basic wind turbine characteristics}

In the wind energy conversion system, the power captured from wind is defined as

$$
P_{\text {turb }}=(1 / 2) \cdot C_{p}(\lambda, \beta) \cdot \rho \cdot R_{\text {turb }}^{2} \cdot \pi \cdot V_{\text {wind }}^{3}
$$

where there is $\lambda=\omega_{r} \cdot R_{\text {turb }} / V_{\text {wind }}$.

Dependence of the coefficient $C_{p}$ on $B$ is usually provided by the wind turbine manufacturer in the form of a set of non-dimensional curves. Because of the relationship between $C_{p}$ and $\lambda$, as the speed changes for a given wind velocity, there is a turbine speed which gives maximum output power. This is a characteristic of various wind speeds. The peak power for each wind speed occurs at the point where $C_{p}$ is maximized. In order to maximize the generated power, it is desirable for the generator to have a power characteristic that will follow the maximum $C_{p}$ curve $[16,17]$.

\subsection{Control system configuration}

The control structure of the variable-speed wind energy conversion system with cage induction generator has two levels of regulation: control of an AC-DC-AC converter and control of the wind turbine. The control of an AC-DC-AC converter consists of two decoupled control channels. One of them is used to control the grid-side converter whereas the other is used to control the generatorside converter using the sensorless vector control 
technique [18]. This configuration provides maximal utilization of wind energy, injection of reactive power into the grid and compensation of reactive power in cases of "weak grid" or faults in the system despite the use of an induction machine [18]. The control of the wind turbine has two regulators: one for speed and another one for power. They are cross connected and give the references to the system for the pitch and blade control as well as a reference for the generated active power [19].

\section{Indirect sensorless vector control of the induction generator}

A control algorithm of the induction generator with an indirect sensorless rotor flux oriented vector control is shown in Figure 1. The torque and flux producing stator current references $i_{s q}^{*}$ and $i_{s d}^{*}$ are generated from the electromagnetic torque and flux references, respectively. In order to perform vector control there are numerous possibilities for obtaining the angle of orientation $\theta_{d q}$. One is to monitor the shaft speed and calculate the slip angle [20]. For this solution, it is necessary to use an encoder or some other shaft-speed sensor. As mentioned above, the use of an encoder detracts from the inherent robustness of cage induction machines. The second solution, which is presented here, is based on the sensorless control technique.

Various solutions for sensorless drives have been proposed in the past decade. These methods could be broadly classified into two main categories [21]. The first approach is based on the mathematical model of induction machines, while the second approach considers some so-called secondary effects such as the rotor slot harmonics in the air-gap field and the triple harmonics stator emf caused by saturation of the stator core, among others. These secondary effects also offer the potentiality for speed estimation. Among the approaches described above, MRAS speed estimators are the most attractive because of the simplicity of their design [22, 23]. The use of an MRAS observer seems to be one of the most feasible approaches to implementing adaptive control systems. The primary characteristic of an adaptive system is the presence of a reference model, which can appear under various forms.

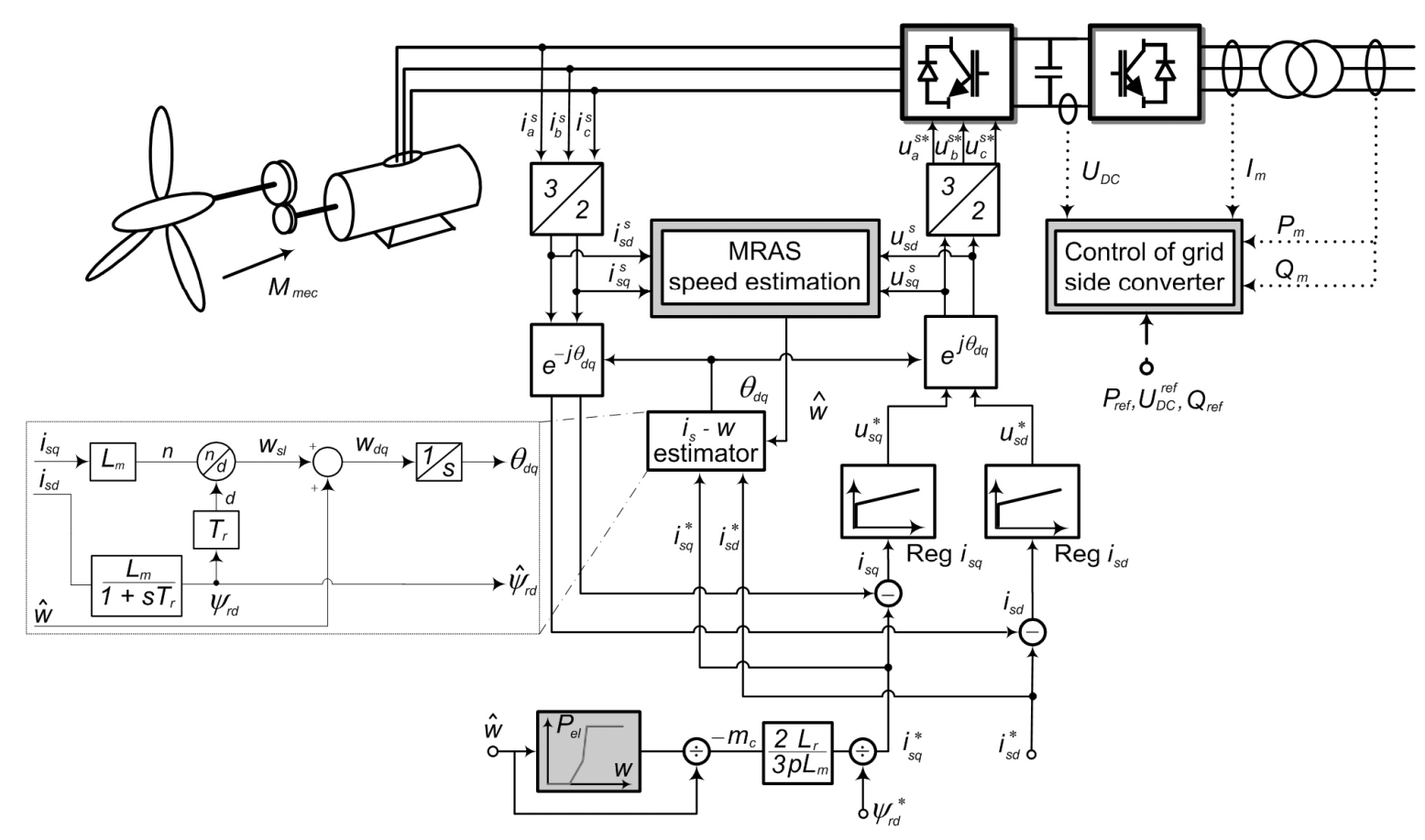

Figure 1. Schematic of the indirect vector control of an induction generator in shaft sensorless WECS. 


\section{MRAS observer - Model Reference Adaptive System}

Adaptive control has emerged as a solution for implementing high performance control systems, especially when the dynamic characteristics of a drive are unknown or have large and unpredictable variations [7]. The method discussed in this paper is the rotor flux based MRAS observer. By using the MRAS observer, it is possible to reduce the influence of parameter mismatch on the position estimation. The observer is based on two models, a reference (voltage) model and an adjustable (current) model. An adaptive mechanism, in this case a PI regulator, is used to eliminate the error. The voltage model used to obtain the rotor flux is defined using the following equation [9]:

$p \underline{\hat{\psi}}_{r V}^{s}=\frac{L_{r}}{L_{m}}\left[\underline{u}_{s}^{s}-\left(R_{s}+\sigma L_{s} p\right) \cdot \underline{i}_{s}^{s}\right]$

Otherwise, the rotor flux can be also calculated from the adjustable (current) model as

$$
p \underline{\hat{\psi}}_{r C}^{s}=\frac{L_{m}}{T_{r}} i_{s}^{s}-\left(\frac{1}{T_{r}}-j \hat{\omega}\right) \cdot \hat{\hat{\psi}}_{r}^{s}
$$

In the MRAS observer, the flux obtained from (2) is used as a reference. If we know the values of all parameters and rotor speed, then the outputs of both the reference model and the adjustable model should match. Any mismatch between the speeds of the generator and the adjustable model would automatically result in an error between the outputs of the two estimators. This is the error between the rotor flux reference and the estimated rotor flux that will be used to adjust the speed of the adaptive model. The error between the estimated quantities obtained by the two models is used to drive a suitable adaptation mechanism which generates the estimated rotor speed for the adjustable model. The proportional-integral controller uses error as feedback so that an adaptation algorithm can tune the speed until error equals zero. The adaptive model is adjusted until satisfactory performance is achieved. The error in the stationary $d^{s}-q^{s}$ reference frame is defined as

$\varepsilon_{\omega}=\underline{\hat{\psi}}_{r C}^{s} \times \underline{\hat{\psi}}_{r V}^{s}=\hat{\psi}_{r d C}^{s} \cdot \hat{\psi}_{r q V}^{s}-\hat{\psi}_{r q C}^{s} \cdot \hat{\psi}_{r d V}^{s}$
Equations (2) to (4) are used to implement the MRAS observer. The error calculated using (4) is driven to zero using a PI controller. The output of this controller is the estimated rotational speed $\hat{w}$, which is used later in calculating the reference for the torque current. The implementation of the MRAS observer is shown in Figure 2.

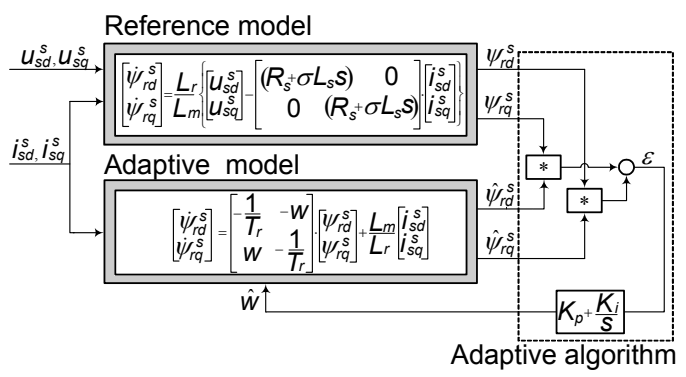

Figure 2. Speed shaft estimation of the induction machine using MRAS.

On the basis of previous equations and sensorless control structure, a simulation in Matlab/Simulink is carried out. The drive is alternately loaded and unloaded with half the nominal torque, starting from 1 second every 0.1 seconds. It is assumed that the parameters are equal to the nominal one, i.e., the parameter mismatch is not taken into account. The simulation results are shown in Figure 3 . In the experimental realization of the MRAS observer, the reference model cannot be implemented using a pure integrator [7]; instead, the transfer function $1 /(p+1 / p)$ is used in the experiments presented in this paper.

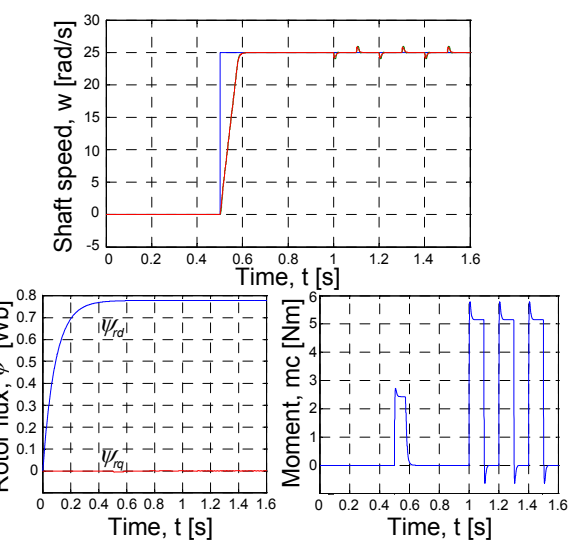

Figure 3. Reference, actual and MRAS estimated shaft speed of the induction machine, rotor flux and conversion moment of induction machine - simulation. 


\section{Stationary state model and parameter mismatch}

A problem with model-based techniques for estimating speed is the sensitivity to machine parameter variation effects. The estimation of speed is normally complex and heavily dependent on machine parameters. Parameter mismatch in the sensorless vector drive is in some way different when it comes to drives with sensors. For example, stator resistance has a great influence on speed estimation in sensorless vector drives, whereas in drives with sensors its influence is negligible. In this section, a stationary state mathematical model is developed. Equations (5) to (8) represent the mathematical model of a vector controlled induction generator without shaft speed sensor in a variable speed WECS. The generator shaft speed estimation is realized based on the $i_{s}-w$ estimator mentioned earlier.

$$
\begin{gathered}
\left(R_{s}-R_{s m}\right) i_{s d}^{*}-\left(W+\frac{i_{s q}}{T_{r} i_{s d}}\right) . \\
\left(\left(\left(L_{\gamma s}+L_{m}\right)-\sigma L_{s}\right) i_{s q}+L_{m} i_{r q}\right)=0 \\
R_{r} i_{r d}-\left(W+\frac{i_{s q}}{T_{r} i_{s d}^{*}}-\omega\right)\left(\left(L_{\gamma r}+L_{m}\right) i_{r q}+L_{m} i_{s q}\right)=0 \\
R_{r} i_{r q}+\left(W+\frac{i_{s q}}{T_{r} i_{s d}^{*}}-\omega\right)\left(\left(L_{\gamma r}+L_{m}\right) i_{r d}+L_{m} i_{s d}\right)=0
\end{gathered}
$$

$$
m_{c}=-\frac{3}{2} \kappa L_{m}\left(i_{s q} i_{r d}-i_{s d}^{*} i_{r q}\right)
$$

In the above equations, $R_{s m}$ is the value of stator resistance of the induction generator, which is set in the MRAS observer, $W$ is the stationary value of the estimated speed and $\omega$ is the actual speed of the induction generator rotor.

The following figures present simulation results which are obtained based on Equations (5) to (8). The first simulation demonstrates the influence of stator resistance mismatch, whereas all the other parameters are considered to be constant. The stator resistance is supposed to be $20 \%$ higher than the nominal one. An error can be noted in the rotor speed estimation, as well as one in the flux vector orientation. The error in the flux vector orientation contributes to the higher value of flux $\psi_{\text {rq }}$ and lower value of flux $\psi_{r d}$. In addition, the mathematical model developed is used to analyze the impact of changes in the rotor resistance on the characteristic values of the controlled system. The rotor resistance mismatch influences the estimated speed only but does not affect the flux vector orientation; this is shown in Figure 5. An error in the estimated rotor speed leads to an incorrect power reference within the variable speed WECS.
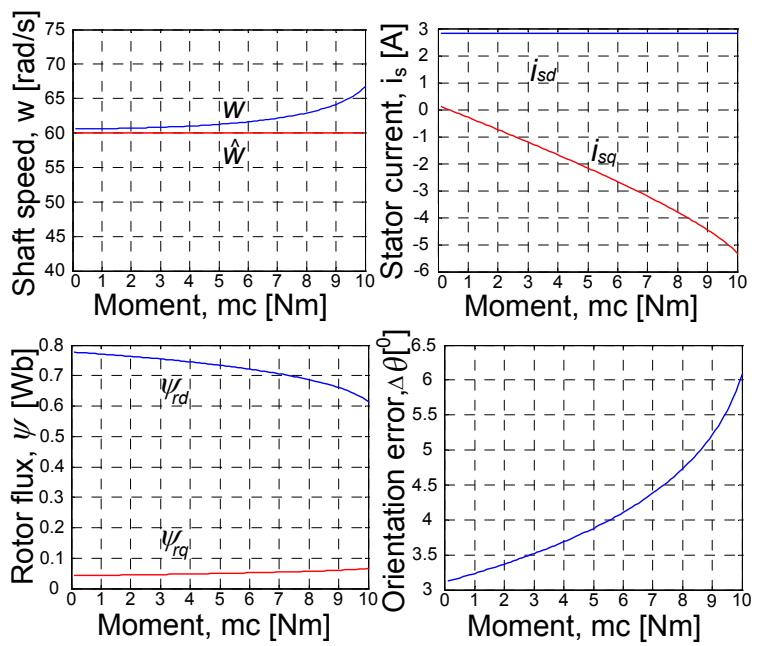

Figure 4. Shaft speed, currents, fluxes and field orientation of induction generator when stator resistance is $120 \%$ of the nominal value.
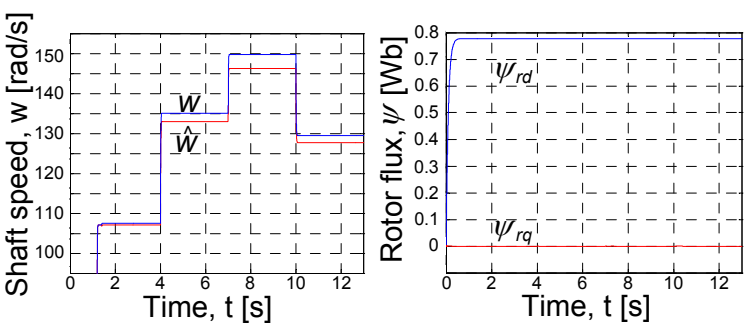

Figure 5. Shaft speeds and fluxes of induction generator when rotor resistance is $120 \%$ of the nominal value.

If machine parameters are not accurately known, the speed estimation and the rotor flux orientation are influenced. The control mechanism will therefore fail to work in maximum power tracking mode because of such a stationary-state speed 
estimation error. This will lead to losses in generating power. In the non-limit zone it is possible to find the exact amount of power loss using the following equation:

$$
\Delta P_{e l}=\frac{1}{2} \pi \rho R_{\text {turb }}^{3} V_{\text {wind }}^{2}\left[\frac{d C_{p}(\lambda, \beta)}{d \lambda}\right]\left(\hat{\omega}-\omega_{\text {ropti }}\right)
$$

where $w_{\text {ropti }}$ is the optimal rotor speed of the induction generator for the given wind speed.

The error in field orientation and power loss when the stator resistance is not constant is shown in Figure 6 . These results are obtained from dynamic Matlab/Simulink model when the stator resistance is constantly detuned by $20 \%$ from the nominal value and generator power is increased from zero to the nominal value. At a full load there is power loss of $3 \%$ from the nominal power (parameters used in this simulation correspond to the machine parameters utilized in the experimental setup, $\left.\Delta P / P_{\text {nom }}=50 / 1500=3 \%\right)$.
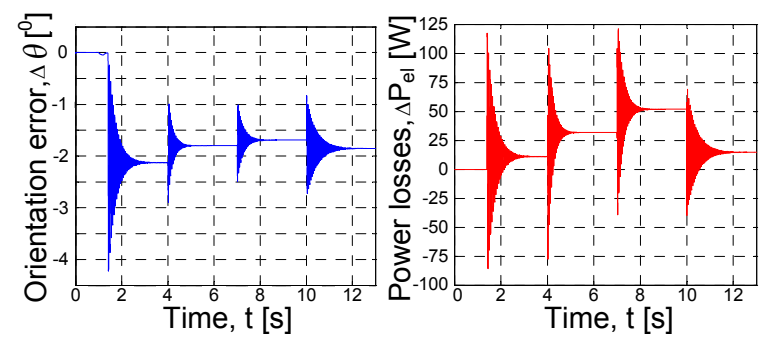

Figure 6. Error in field orientation and power losses.

From the discussion above, it is evident that the estimation of shaft speed is highly parametersensitive. Accurate acquisition of parameters is necessary for accurate speed estimation.

\section{Parallel stator resistance and rotor speed estimation}

The configuration of the proposed parallel rotor speed and stator resistance estimation is shown in Figure 7 and is discussed in detail further on.

For the purpose of deriving an adaptation mechanism, it is valid to initially treat rotor speed as a constant parameter since it changes slowly compared to change in rotor flux. Let $R_{s}$ and $w$ denote the true values of the stator resistance in

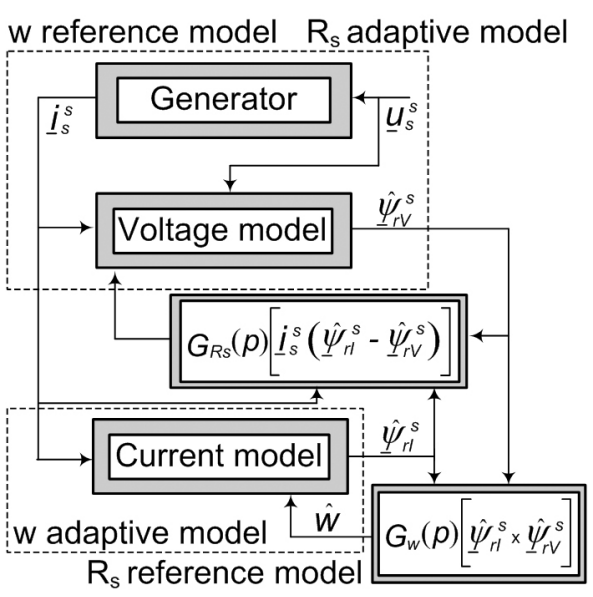

Figure 7. Parallel resistance and speed estimation.

the machine and the rotor speed, respectively. These are in general different from the estimated values. Consequently, a mismatch between the estimated and true rotor flux space vectors appears as well. The error equations for the voltage and the current model outputs in the stationary reference frame can be represented as

$$
\begin{aligned}
& p_{\underline{\varepsilon}_{V}}=-\frac{L_{r}}{L_{m}}\left(R_{s}-\hat{R}_{s}\right) \cdot \underline{i}_{s}^{s} \\
& \underline{\varepsilon}_{V}=\underline{\psi}_{r V}^{s}-\underline{\hat{\psi}}_{r V}^{s}=\varepsilon_{d V}^{s}+j \varepsilon_{q V}^{s} \\
& p_{\underline{\varepsilon}_{C}}=\left(j \omega-\frac{1}{T_{r}}\right) \underline{\varepsilon}_{C}+j(\omega-\hat{\omega}) \underline{\psi}_{r C}^{s} \\
& \underline{\varepsilon}_{C}=\underline{\psi}_{r C}^{s}-\underline{\hat{\psi}}_{r C}^{s}=\varepsilon_{d C}^{s}+j \varepsilon_{q C}^{s}
\end{aligned}
$$

where symbols, $\underline{\Psi}_{r v}^{s}, \underline{\Psi}_{r C}^{s}$ in (11) and (13) stand for true values of two rotor flux space vectors.

An adaptive mechanism for speed estimation is already known, (Figure 2), and represented as

$$
\hat{\omega}=\left(K_{p \omega}+\frac{K_{l \omega}}{p}\right) e_{\omega}
$$

where $K_{p w}$ and $K_{/ w}$ are $\mathrm{Pl}$ controller parameters of the rotor speed adaptation mechanism.

For stator resistance estimation, the reference and adjustable model, Figure 7 , must be switched. Therefore, the error quantity for stator resistance estimation is 


$$
\varepsilon_{R s}=i_{s d}^{s}\left(\hat{\psi}_{r d V}^{s}-\hat{\psi}_{r d C}^{s}\right)+i_{s q}^{s}\left(\hat{\psi}_{r q V}^{s}-\hat{\psi}_{r q C}^{s}\right)
$$

The adaptive mechanism for the stator resistance estimation is given as

$$
\hat{R}_{s}=\left(K_{p R s}+\frac{K_{I R s}}{p}\right) e_{R s}
$$

where $K_{p R s}$ and $K_{I R s}$ are PI controller parameters of the stator resistance adaptation mechanism.

The rotor speed and stator resistance can be estimated in parallel using (14) and (16) at any generator speed. The rotor speed adaption mechanism is the same as in the customary MRAS speed estimator reviewed in Section 4. The stator resistance is estimated in the stationary reference frame and the error quantity is obtained using two rotor flux space vectors. The stator resistance and the rotor speed estimation operate in parallel.

A sample of simulation results is presented in Figure 8. The actual stator resistance of the induction generator in the sensorless vectorcontrolled WECS, shown in Figure 1, is set from the start as $20 \%$ lower than the nominal generator resistance. The value in the estimator in Figure 2 is set to nominal. Upon completing the transient there is a substantial speed estimation error as well as a substantial error in the rotor flux. The stator resistance adaptation mechanism is switched on at $3.5 \mathrm{~s}$ and turbine torques increase at $7 \mathrm{~s}$. The activation of the stator resistance adaptation mechanism corrects initial stator resistance error.
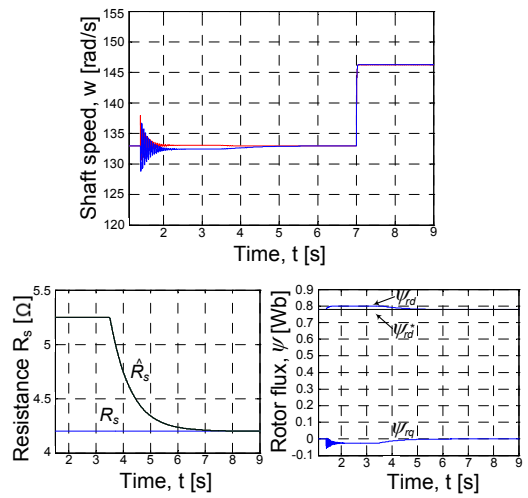

Figure 8. Verification of parallel speed and stator resistance estimation by simulation: actual and estimated speed, stator resistance in generator and stator resistance estimated, rotor flux reference and rotor flux $d-q$ axis components.
The speed estimate converges towards the actual speed and correct rotor flux orientation is established, meaning that the rotor flux $q$-axis component reduces to zero, with simultaneous equalization of the rotor flux $d$-axis component at the reference rotor flux value. Subsequent turbine torque changes have no effect on the accuracy of either the speed estimate or the stator resistance estimate.

\section{Experimental results}

Experimental verifications of the foregoing theoretical considerations are presented and analyzed in this section. A $1.5 \mathrm{~kW}, 380 \mathrm{~V}$, nominal frequency of $50 \mathrm{~Hz}$, four-pole cage induction generator is utilized in the experimental prototype. One laboratory prototype inverter with $16 \mathrm{kHz}$ switching frequency and one commercial inverter are used. On the generator side, two line currents are measured via two Hall sensors. To avoid noise, the measured currents are filtered by two low-pass filters with a cut-off frequency of about $2 \mathrm{kHz}$. A speed encoder of $3600 \mathrm{ppr}$ is used to calculate the system speed. This speed signal is not used in the control algorithms and is only used for comparison purposes. The voltage transducer is used to measure DC link voltage. The generator is driven by a torque controlled $2.2 \mathrm{~kW}$, two-pole induction motor drive that simulates a wind turbine.

The experimental setup is shown in Figure 9. Taking into account that the general principles of work are the same and the loss structure is similar for induction machines of different sizes, the experimental setup yields realistic verifications of theoretical considerations [24, 25].

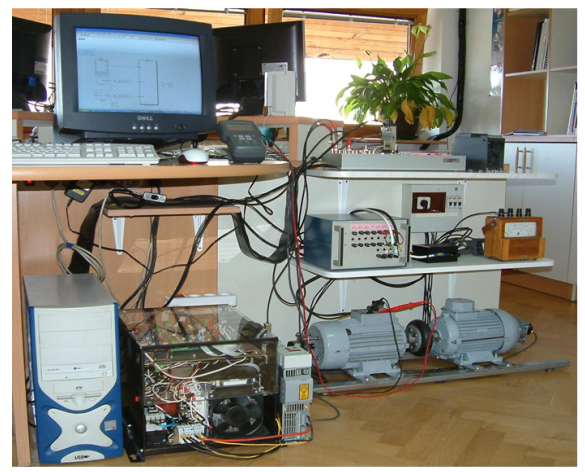

Figure 9. Experimental setup. 
Control algorithms are realized using the ACE1104 developing system based on the DS1104 control board, with a PowerPC $603 \mathrm{e}$ processor. The complete software is developed in Matlab/Simulink and Total Development Environment - TDE [26]. The control structure is programmed as a Simulink graphic model and is implemented by Real Time Interference - RTI on the DS1104 R\&D Controller Board. The RTI is used to connect the model to the physical hardware. The Real-Time Workshop converts the model to $C$ code. The $C$ code is then automatically compiled to the assembly language of the target processors, assembled, link-edited and downloaded. Finally, ControlDesk software is used to run, adjust and monitor the controlled system. The sensorless control of the induction generator in the variable-speed WECS is implemented in three tasks and two layers. The measure task is directly triggered by the PWM interrupt of the slave DSP TMS320F240 subsystem. It works at a PWM frequency of $16 \mathrm{kHz}$ and generates a synchronized software interrupt with an $8 \mathrm{kHz}$ frequency. This interrupt is used to trigger the superior current control task. The subordinated torque control of the induction generator works in a third task and is triggered by the timer interrupt of the PowerPC 603e, which occurs with a frequency of $4 \mathrm{kHz}$.

The control strategies proposed in this paper have been tested in several experiments. First, system response during startup is tested. Speed estimation is performed using the MRAS observer, shown in Figure 2. Experimental results are shown in Figures 10 and 11. Figure 10 shows actual and estimated shaft speed during the startup of the induction generator.

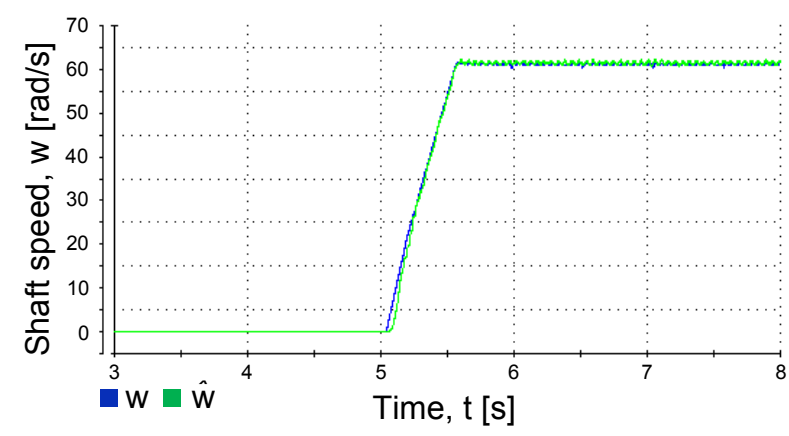

Figure 10. Actual and estimated shaft speed during startup.
At 5 seconds, a drive machine is started with constant torque of $1 \mathrm{Nm}$. It can be noted that at startup there is a slight mismatch between actual and estimated speeds; but after that, the estimated speed almost perfectly matches the actual shaft speed of the induction generator. The experimental results shown in Figure 11 were obtained using the estimated speed. The speed signal obtained from the encoder was used only to check the results. From 0 to 8 seconds, the system works without drive machine (turbine simulator) starting torque. After that, the torque of the drive machine was incrementally increased. A torque step (wind step) is not realistic but it is the most drastic change from the control system point of view. Again, it can be noted that at the very beginning there is a slight mismatch between actual and estimated speeds, but subsequently the estimated speed almost perfectly matches the actual rotor speed of the induction generator. The variable speed WECS is completely stable from zero.

Speed estimation applying the MRAS type estimator analyzed in this paper can lead to inaccuracy because of parameter variation. It can lead to losses in generated power and endanger drive stability. Figure 12 shows experimental results when the stator resistance of the induction generator is increased to $120 \%$ of the nominal value.

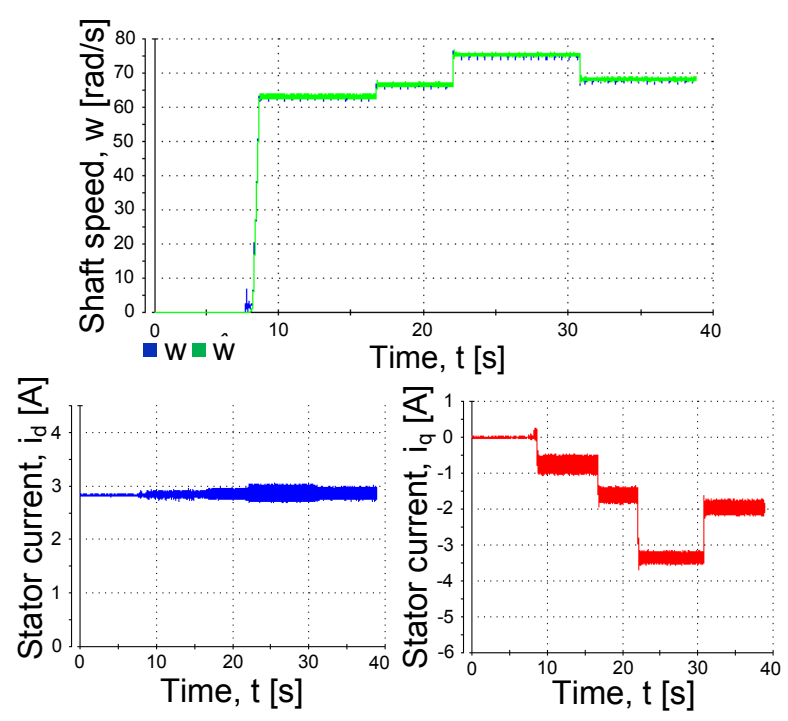

Figure 11. Actual and estimated speed and flux and torque currents with $w$ estimated feedback. 


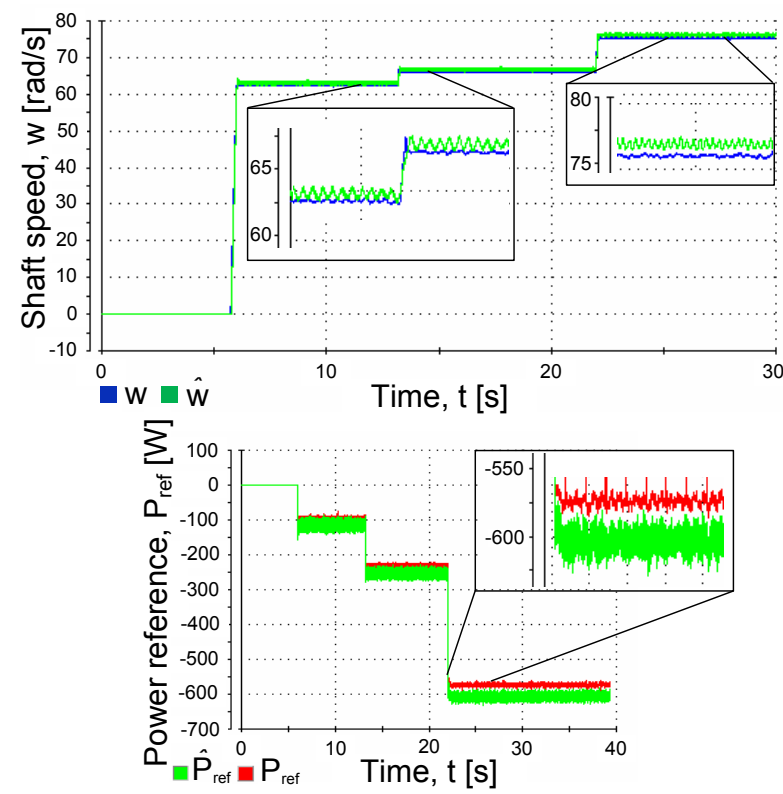

Figure 12. Estimated and actual shaft speed and power reference when $R_{s}=1,2 \cdot R_{n}$.

The experimental system is allowed to operate with a detuned stator resistance in the generator and in the MRAS observer. From 0 to 6 seconds, the system works without starting torque of the drive machine. After that, the torque of the drive machine was set to $1.8 \mathrm{Nm}$, then at 14 seconds $3.7 \mathrm{Nm}$ and at 22 seconds $7.3 \mathrm{Nm}$. A significant deviation can be observed between the estimated and actual shaft speed as the generator load is increased. An error in the estimated speed causes an error in the active power reference.

The other important parameter that appears in (2) and (3) is the rotor time constant. The rotor resistance also varies due to heating in the electrical drive. Figure 13 shows experimental results when the rotor resistance is detuned to the nominal value. From 0 to 5 seconds, the system works without starting torque of the drive machine. After that, the torque of the drive machine is set to $1.8 \mathrm{Nm}$, then at 13 seconds $3.7 \mathrm{Nm}$, at 19 seconds $7.3 \mathrm{Nm}$. It can be concluded that variation in rotor resistance influences speed estimation, which is reflected in the incorrect active power reference.

Finally, a proposed parallel stator resistance and rotor speed estimation algorithm are experimentally validated. The experimental system is allowed to operate initially with a detuned stator resistance in certain steady state, and the stator resistance estimator is then switched on (at 20 seconds). Figure 14 illustrates the process of speed estimation and stator resistance estimation for nominal load operation of the induction generator.

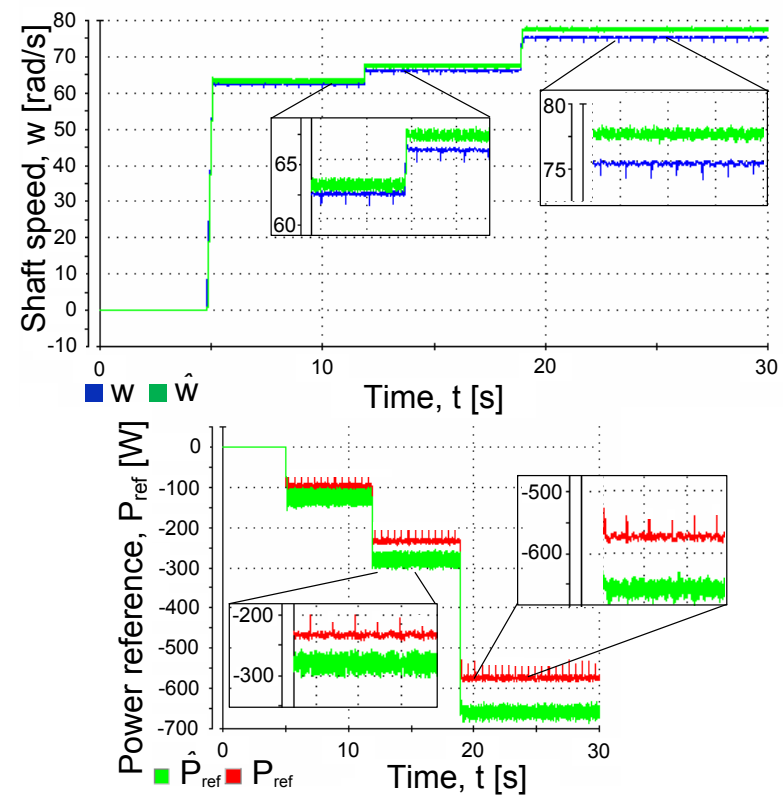

Figure 13. Estimated and actual shaft speed and power reference when $R_{r n}=1,2 \cdot R_{r}$
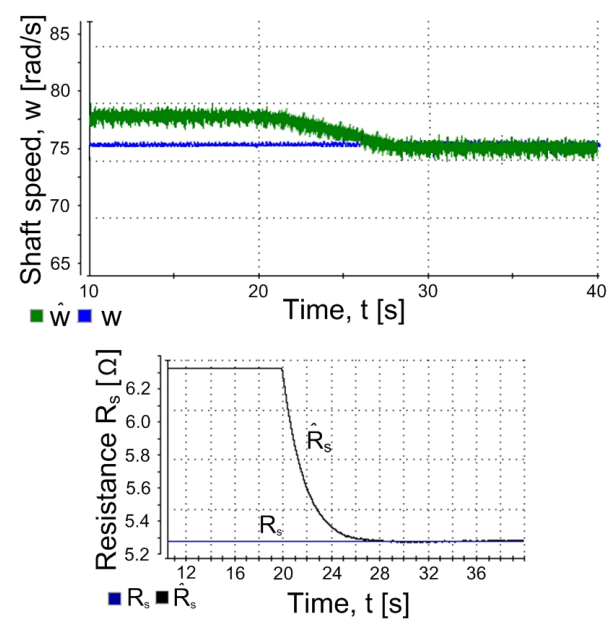

Figure 14. Experimental verification of parallel estimation scheme - estimated and actual generator shaft speed, estimated and actual generator stator resistance (adaptation mechanism is activated at 20 seconds). 
The initial detuning in the stator resistance is $20 \%$. As can be seen in Figure 14, the activation of the stator resistance adaptation mechanism quickly compensates the initial error in the estimated stator resistance value, and therefore compensates the initial speed estimation error.

\section{Conclusion}

This paper has presented a sensorless vector control strategy for an induction generator and effects of parameter mismatch in a variable speed WECS. The MRAS observer, based on the voltage model and the current model, is used to estimate the shaft speed. Speed estimation applying the MRAS observer can lead to inaccuracy because of the parameter variation. The mismatch of the stator resistance influences the flux vector orientation and the estimated speed. The mismatch of the rotor resistance influences the estimated speed only. An error in the estimated speed leads to losses in generated power and together with an error in flux vector orientation can endanger the stability of the WECS. In order to improve the efficiency of a WECS, a parallel MRAS estimator is presented. It enables a simultaneous estimation of the rotor speed and the stator resistance of the induction generator. The proposed parallel MRAS system is slightly more complex than its counterpart with speed estimation only and enables accurate speed estimation. The effectiveness of the structure developed is verified by simulation and by extensive experimental testing. The capability of the WECS to start from zero speed in sensorless mode is demonstrated.

\section{Appendix - explanation of symbols}

\section{Superscripts \\ 2. Subscripts: \\ $s, r$ \\ $V, C$ \\ $n$}

* Reference value.

$s \quad$ Stationary reference frame.

3. Other:

Above symbol denotes estimated
value.
Underlined variables are space
vectors.

\section{Acknowledgements}

This paper is a result of the scientific project No. III 042004 of Integrated and Interdisciplinary Research entitled "Smart Electricity Distribution Grids Based on Distribution Management System and Distributed Generation“ funded by Republic of Serbia, Ministry of Education and Science.

\section{References}

[1] D. Hansen, H. Hansen, "Wind Turbine Concept Market Penetration over 10 Years", Wind Energy, vol. 10, pp. 81-97, Nov. 2006. Available: http://dx.doi.org/10.1002/we.210

[2] T. Ahmed et al., "Advanced Control of PWM Converter With Variable-Speed Induction Generator", IEEE Trans. on Industry Application, vol. 42, no. 4, pp. 934-945, Jul./Aug. $2006 . \quad$ Available: http://dx.doi.org/10.1109/TIA.2006.876068

[3] Z. Chen et al., "A Review of the State of the Art of Power Electronics for Wind Turbines", IEEE Transactions on Power Electronics, Vol. 24, no. 8, August 2009. Available: http://dx.doi.org/10.1109/TPEL.2009.2017082

[4] A. Miller et al., "A Variable Speed Wind Turbine Power Control”, IEEE Trans. on Energy Conversion, vol. 12, no. 2, pp. 181-186, Jun. 1997. Available: http://dx.doi.org/10.1109/60.629701

[5] R. Decher, "Energy Conversion: Systems, Flow physics and Engineering", Oxford University Press, New York, 1994.

[6] F. Blaabjerg et al., "Trends in Power Electronics and Control of Renewable Energy Systems", Proceedings of 14th International Power Electronics and Motion Control Conference, K1-K19, EPE-PEMC 2010.

[7] P. Vas, "Sensorless Vector and Direct Torque Control”, Oxford University Press, New York 1998.

[8] M. Hinkkanen et al., "Reduced-Order Flux Observers With Stator-Resistance Adaptation for Speed-Sensorless Induction Motor Drives", IEEE Trans. on Power Electronics, Vol. 25, no.5, May 2010. Available: http://dx.doi.org/10.1109/TPEL.2009.2039650.

[9] V. Vasic et al., "A Stator Resistance Estimation Scheme for Speed Sensorless Rotor Flux Oriented Induction Motor Drives", IEEE Trans. on Energy Conversion, vol. 18, no. 4, pp. 476 - 483, Dec. 2003. Available: http://dx.doi.org/10.1109/TEC.2003.816595 
[10] F. Kulic et al., "Optimal Fuzzy Controller Tuned by TV-PSO for Induction Motor Speed Control", Advances in Electrical and Computer Engineering, vol. 11, no. 1, pp. 49-54, 2011. Available: http://dx.doi.org/10.4316/AECE.2011.01008

[11] B. Wu et al., "Power Conversion and Control of Wind Energy Systems", IEEE press, NJ, 2011.

[12] R. Cardenas, R. Pena, "Sensorless Vector Control of Induction Machines for Variable-Speed Wind Energy Applications", IEEE Trans. on Energy Conversion, vol. 19, no. 1, pp. 196-205, March 2004. Available: http://dx.doi.org/10.1109/TEC.2003.821863

[13] T. Senjyu et al., "Wind Velocity and Rotor Position Sensorless Maximum Power Point Tracking Control for Wind Generation System", pp. 1764-1775. Renewable Energy 31, 2006.

[14] M. Tsuji et al., "A Sensorless Vector Control System for Induction Motors Using q-Axis Flux with Stator Resistance Identification", IEEE Trans. on Industrial Electronics, vol. 48, no. 1, pp. 185-194, Feb. 2001.

[15] E. Mitronikas, A. Safacas, "An Improved Sensorless Vector-Control Method for an Induction Motor Drive", IEEE Trans. on Industrial Electronics, vol. 52, no. 6, pp. 1660-1668, Dec. 2005.2 Available: http://dx.doi.org/10.1109/TIE.2005.858706

[16] L. Mihet-popa, V. Groza, "Modeling and Simulation of a 12 MW Wind Farm", Advances in Electrical and Computer Engineering, vol. 10, no. 2, pp. 141-144, 2010. Available: http://dx.doi.org/10.4316/AECE.2010.02025

[17] V. Calderaro et al., "A Fuzzy Controller for Maximum Energy Extraction from Variable Speed Wind Power Generation Systems", Electric Power Systems Research, Volume 78, Issues 6, pp.1109 - 1118, June 2008.

[18] B. Dumnic et al., "Optimal MRAS Speed Estimation for Induction Generator in Wind Turbine Application", The 15th IEEE Mediterranean Electromechanical Conference-MELECON 2010, April 25th - 28th, 2010, Valletta, Malta, pp. 949-954, IEEE Catalog Number CFP10MEL-CDR.

[19] K. Johnson, "Adaptive Torque Control of Variable Speed Wind Turbines", National Renewable Energy Laboratory, Colorado, 2004. Available: http://dx.doi.org/10.2172/15008864.

[20] B. K. Bose, "Modern Power Electronics and AC Drives", Prentice Hall PTR, NJ, 2001.
[21] J. Holtz, "Perspectives of Sensorless AC Drive Technology", 27th International PCIM Europe, Nuremberg, 2005, pp. 80-87, Jun. 2005.

[22] C. Schauder, "Adaptive speed identification for vector control of induction motors without rotational transducers", IEEE Transaction on Industry Applications, No. 5 , pp. 1054-1061, 1992. Available: http://dx.doi.org/10.1109/28.158829

[23] A. Paladugu, B. H. Chowdhury, "Sensorless control of inverter-fed induction motor drives", Electric Power Systems Research, Volume 77, Issues 5-6, pp. 619-629, April 2007.

[24] R. Teodorescu et al., "Advanced Education Facilities for Power Electronics and Renewable Energy Systems at Aalborg University", The International Power Electronics Conferences - IPEC 2005, April 6th - 10th, Niigata, Japan, pp. 533-540.

[25] M. A. Arjona et al., "Development of a SynchronousGenerator Experimental Bench for Standstill TimeDomain Tests", Journal of Applied Research and Technology, Vol.9, No.2, pp. 117 - 128, August 2011.

[26] dSpace, "Solutions for Control, DS1104 R\&D Controller Board”, Paderborn, Germany, 2008. 